\title{
Blogs segundo a tipologia textual baseada em contexto: proposta para análise textual em estudos da traduccấo
}

\author{
Blogs in context based text typology: \\ a proposal for textual analysis in translation studies
}

Edelweiss Vitol Gysel

Universidade Federal de Santa Catarina

Maria Lúcia B. de Vasconcellos

Universidade Federal de Santa Catarina

Elaine Espindola

Polytechnic University Hong Kong

\begin{abstract}
Resumo: Este trabalho tem como objetivo apresentar resultados de uma pesquisa desenvolvida na interface entre Linguística Sistêmico-Funcional (LSF) e Estudos da Tradução com foco em Tipologia Textual baseada em contexto. A base teórica do trabalho está assentada na proposta de ‘Atividades Sociossemióticas', representada graficamente na chamada Esfera de Atividades Sociossemióticas, de Matthiessen, Wu e Teruya (2007). Apresenta-se inicialmente uma coleta de dados (blogs) compilados em formato eletrônico e relativos às tipologias textuais nos contextos do português brasileiro ( $\mathrm{PB}$ ) e inglês americano (IA). A seguir, apresenta-se a classificação dos textos coletados nesses blogs com base nas 'Atividades sociossemióticas'. Após a classificação sócio semiótica, uma análise de transitividade é realizada com vistas a explorar a relação entre a Tipologia Textual baseada em contexto e os padrões gramaticais do sistema de transitividade que realizam os diferentes tipos textuais. Por fim os resultados dessa análise são comparados
\end{abstract}

1. Este artigo éresultado de pesquisa desenvolvida junto ao Programa de Pós-Graduação em Estudos da Tradução/ PPGET, na Universidade Federal de Santa Catarina/UFSC, em 2013, sob a orientação conjunta das co-autoras. 
para fins de identificar diferenças e semelhanças nas configurações texto-contextuais dos dois conjuntos de textos produzidos em ambos os idiomas. Os desdobramentos dessa comparação buscarão traçar um perfil ‘sociossemiótico’dos textos analisados, com vistas

Edelweiss a fornecer um modelo de parâmetros textuais para formação de tradutores na dimensão Vitol Gysel bilíngue/ textual do desenvolvimento de suas competências.

Palavras-chave: Estudos da tradução. Tipologia Textual baseada em contexto. Linguística

Maria Lúcia

B. de Vasconcellos

Elaine

Espindola

Sistêmico-Funcional. Blogs.

Abstract: This paper aims at the presentation of the results of research developed in the interface between Systemic Functional Linguistics (SFL) and Translation Studies onContext based Text Typology. The theoretical framework rests on the notion of "Socio Semiotic Activities" graphically represented by SocioSemiotic Activities proposed by Matthiessen, $\mathrm{Wu}$ and Teruya in 2007. First, a collection of data (texts from two blogs) inthe context of Brazilian Portuguese and American English Text Typology taken fromelectronic format is presented. Afterwords, the classification of the selected texts in terms of their Socio Semiotic Activities is exposed, followed by the analysis of transitivityaiming at the understanding of the relationship between Context based Text Typology and the grammatical different patterns of transitivity realized in different types of texts. Last, the results obtained from the analysis of the texts in Brazilian Portuguese (PB) and in American English (IA) are compared aiming at identifying differences and/or similarities in the text and the contextual configurations in the sets of texts produced in both languages. The unfoldings of this comparison will attempt to drawing a Socio-semiotic profile of the texts under study with a view at providing a framework for translators' education in what regards the development of their bilingual/textual subcompetence.

Key words: Translation Studies, Context-based Text Typology, Systemic Functional Linguistics.

\section{Introdução}

Na prática tradutória, o reconhecimento de tipologia textual é de suma importância para o tradutor, pois a perspectiva da dimensão tipológica de textos pode influenciar não só a maneira em que se traduz, mas também a qualidade do produto final, ou seja, a tradução (REISS, 1971, 2000; BELL, 1991; MATTHIESSEN, 2007).

$\mathrm{Na}$ área de Estudos da Tradução, tomamos como representativa a pesquisa sobre Tipologia Textual ressaltada por Bell, que em $1991 \mathrm{em}$ seu estudo intitulado Translation and Translating: Theory and Practice, re- 
força a importância de se propor uma Tipologia Textual compreensível tanto sob aspectos teóricos quanto práticos. Ele afirma que sem a habilidade de reconhecer um texto como amostra de uma forma específica, e em si um símbolo de um tipo específico de texto, o tradutor não seria capaz nem compreendê-lo, nem escrevê-lo e muito menos traduzi-lo. Já Reiss, a pioneira nesse tipo de pesquisa $\left(1971,2000\right.$ p.17) ${ }^{2}$ afirma, sob a perspectiva dos Estudos da Tradução, que "em uma situação normal de tradução é o tipo de texto que decide a abordagem do tradutor; o tipo de texto é o fator primário que influencia a escolha do tradutor por um

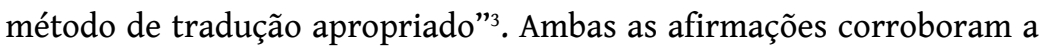
importância da Tipologia Textual para tradução.

A partir de uma perspectiva da tradução, Matthiessen et al. (2007, p.1) apontam que textos em seus contextos de comunicação são a 'matéria-prima' de tradutores e intérpretes, que traduzem 'textos', levando em consideração os contextos nos quais esses são produzidos e consumidos . Eles ainda ressaltam que traduzir um texto é muito mais complexo do que apenas lê-lo, escutá-lo ou vê-lo no dia a dia (considerando aqui texto escrito, falado e sinalizado). Reiss, Bell e Matthiessen concordam que, para tradutores, a análise textual se faz necessária, pois revela muito mais significados de um texto 'empoderando' tradutores em seu fazer tradutório. Essa análise textual dá aos tradutores conhecimento da especificidade de cada tipo textual gerando consequências positivas deste conhecimento para a prática de tradução, a fim de que o texto esteja de acordo com as convenções genéricas, ou seja, as convenções que regem o tipo textual em contextos de partida e de chegada.

Assim sendo, a premissa que informou o estudo aqui relatado é de que a análise textual é parte inerente do processo de traduzir textos como unidade de significado em contexto e não um esforço separado da atividade tradutória (MATTHIESSEN et al., 2009), o que explica sua centralidade na formação de tradutores: no exercício da análise textual é possível para o tradutor em formação adquirir a habilidade de lidar com texto e linguagem e expandir seu repertório de registros.

No presente estudo, considera-se a variável 'campo', definida por

\footnotetext{
2. Todas as citações são traduzidas pelas autoras deste artigo no corpo do texto e serão incluídas em sua língua de partida em notas de rodapé.

3. "In this kind of normal situation it is the type of text which decides the approach for the translator; the type of text is the primary factor influencing the translator's choice of a proper translation method."
} 


\section{Edelweiss \\ Vitol Gysel \\ Maria Lúcia \\ B. de Vasconcellos \\ Elaine \\ Espindola}

Halliday e Hasan (1985) como, "um componente abstrato do contexto de situação, como ambiente contextual de um texto: o campo tem uma relação sistemática com a metafunção experiencial, uma vez que realiza significados experienciais." ${ }^{4}$ (p. 29). Nesse sentido, as nuances e detalhes de um texto também podem ser observadas através do comportamento transitivo realizado. Por essa razão, e levando em conta a importância de se entender um texto por meio do reconhecimento de sua tipologia e assim poder trabalhá-lo de forma mais objetiva e clara, este artigo propõe (i) estender o modelo de Tipologia Textual baseada em contexto para os Estudos da Tradução e verificar sua contribuição para a caracterização de textos; (ii) explorar a relação entre a Tipologia Textual baseada em contexto e os padrões gramaticais do sistema de transitividade que realizam os diferentes tipos textuais; (iii) examinar esta relação em um corpus comparável (conjuntos de textos selecionados de dois blogs: um em português brasileiro (PB) e um em inglês americano (IA) definidos segundo critérios determinados), com vistas a verificar a existência ou não de padrões gramaticais do sistema de transitividade que realizam os diversos tipos textuais; (iv) comparar os resultados obtidos nas análises dos dois corpora, com vistas a estabelecer diferenças e semelhanças entre os diferentes registros nas duas línguas em questão.

Este artigo é estruturado como se segue: após esta seção, de caráter introdutório, a subseção (2) apresenta o referencial teórico que informa o estudo; a subseção (3) expõe a metodologia utilizada; a (4) apresenta a análise dos dados e, finalmente, a subseção (5) apresenta reflexões e considerações finais quanto a futuros desdobramentos da pesquisa.

\section{Referencial teórico}

Nesta subseção são exploradas as perspectivas teóricas que informam o desenvolvimento deste trabalho. Abordaremos o campo teórico de Tipologia Textual nos de Estudos da Tradução, subdividos em: (2.1) Tipologia Textual baseada em contexto segundo Matthiessen et al. (2007) e (2.2) metafunção ideacional. As discussões teóricas sobre Tipologia Textual na área de LSF visam a fornecer o suporte necessário para se compreender tanto as decisões metodológicas tomadas quanto o modo de realização das análises feitas pelas autoras deste estudo.

4. "These were the abstract components of the context of situation [...] the field is reflected in the experiential meanings of a text." 


\subsection{Tipologia Textual baseada em contexto}

É a partir da necessidade de uma tipologia que consiga explicar a natureza social do texto, que inevitavelmente representa atividades realizadas por indivíduos envolvidos em um contexto, que os linguistas Christian Matthiessen, Canzhong Wu e Kazuhiro Teruya apresentaram em 2007 um modelo de Tipologia Textual o qual não tem como ponto de partida a forma ou a função, mas a construção propiciada pelo conceito de Atividades Sociossemióticas (ASSs) ${ }^{5}$, que são definidas por Matthiessen et al. (2007, p.16) ${ }^{6}$ como 'aquilo que acontece a nossa volta', ou ainda, 'são atividades realizadas pelos indivíduos envolvidos no contexto' (MATTHIESSEN et al. 2010, p. 95) ${ }^{7}$. Assim sendo, eles partem do princípio que os textos, em suas mais variadas formas (escritos, orais, monológicos, dialógicos, multimodais, sinalizados, etc.), estão inseridos e fazem parte de atividades que realizamos em nosso cotidiano, como dar/ter uma aula, trabalhar em um escritório, ir ao supermercado, alimentar um blog, etc. Por essa razão, essas atividades são chamadas de ASSs, pois representam uma atividade social realizada por indivíduos que fazem parte de um contexto de situação.

Considerando-se texto como 'uma unidade de significado funcionando em um contexto' (MATTHIESSEN, 2007, p. 6) torna-se necessário definir o construto "contexto". Isso é o que, em seu artigo intitulado Text Analysis for Translation and Interpreting de $2009^{8}$, Matthiessen se propõe explicar: "contexto é o ambiente de significados onde um texto opera ou 'as coisas' que dão significado ao texto, por assim dizer" ${ }^{9}$ (p.16). Esse $\mathrm{CS}$, como mostra a figura a seguir, é composto por três variáveis: campo - a área do discurso, o que está acontecendo no contexto; relação - os interlocutores no contexto, isto é, a relação estabelecida entre falantes/ escritores e ouvintes/leitores; e modo - o tipo de linguagem e seu papel

\footnotetext{
5. Matthiessen et al. referem-se, no texto de 2007, a ‘processos sócio semióticos', mas para fins de distinção entre 'processos sociossemióticos' e 'processos de transitividade' os primeiros serão denominados de 'atividades sociossemióticas', de acordo com a própria explicação dada pelos linguistas: "são atividades realizadas pelos indivíduos envolvidos no contexto” (MATTHIESSEN et al. 2010, p. 95).

6. The nature of the socio-semiotic process or "what is going on".

7. "The activity is the social and/ or semiotic process that the interactants in the context are engaged in."

8. Manuscrito.

9. "Context is the environment of meanings in which the text operates - the meanings that surround the text, as it were."
}

Blogs segundo
a tipologia
textual baseada
em contexto:
proposta para
análise textual
em estudos da
tradução 


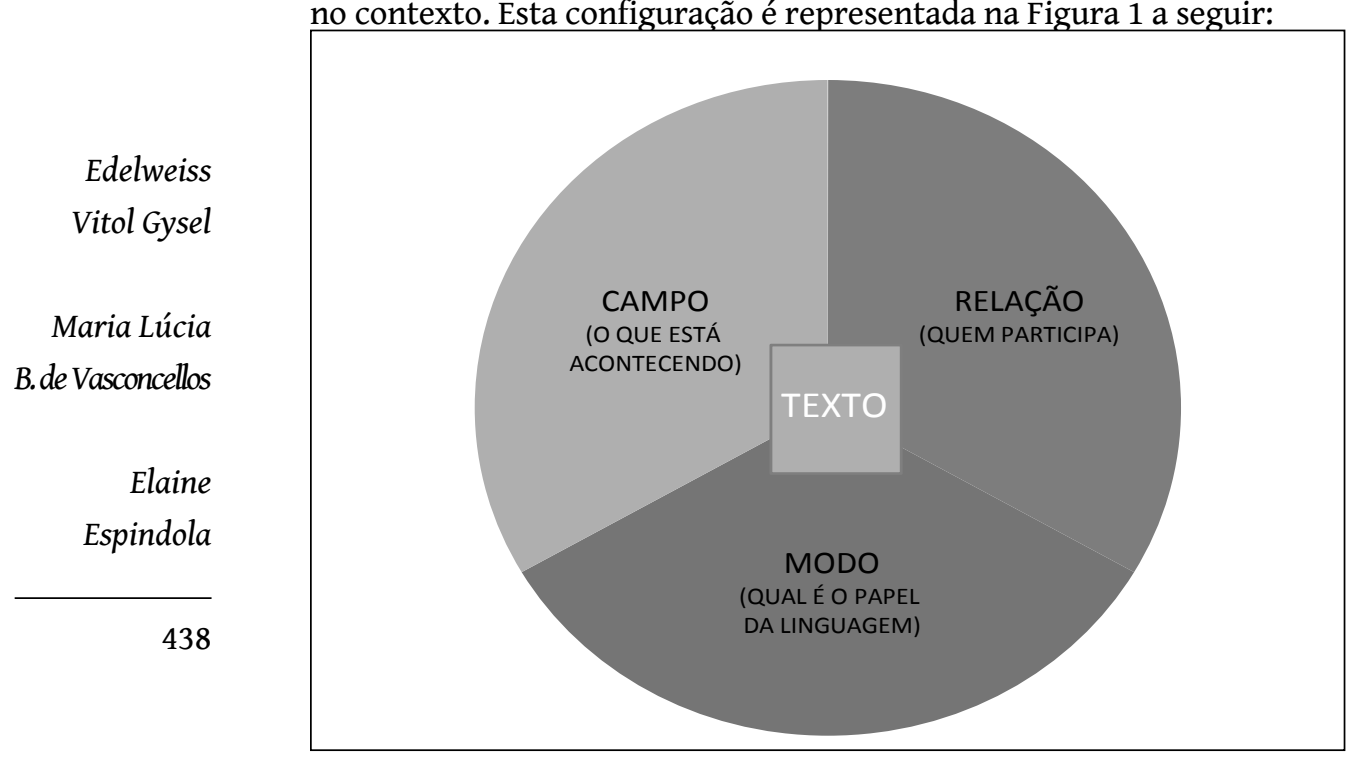

Figura 1 - Texto em contexto: o ambiente de significados de um texto

(MATTHIESSEN, et al., 2009) ${ }^{10}$

Como a Figura 1 mostra, o texto é construído a partir dessas três variáveis que se completam, conferindo-lhe significado. Para fins de pesquisa, é possível isolar e selecionar uma dessas variáveis, dependendo do propósito da investigação. Por exemplo, quando queremos investigar a variação de significado interpessoal, pode-se basear a tipologia em posições de poder e status. Para visualização de sua proposta de ASSs, Matthiessen, Wu e Teruya (2007) apresentam o conceito de esfera tridimensional por eles chamada de "Esfera de Atividades Sociossemióticas ${ }^{11}$ " com vistas a ilustrar as diferentes realizaçãos das ASSs por diferentes tipos de texto, diferenciados quanto à sua natureza monológica ou dialógica, escrita ou oral.

10. Esta figura, idealizada por Matthiessen et al. (2009, p. 19), foi traduzida pela autora deste estudo, a qual optou por essas soluções, não como definitivas, mas como tentativas de oferecer uma tradução em português.

11. No texto de Matthiessen et al. (2007) a esfera é chamada de "Sphere of Socio Semiotic Activities" aqui traduzida por "Esfera de Atividades Sociossemióticas". 


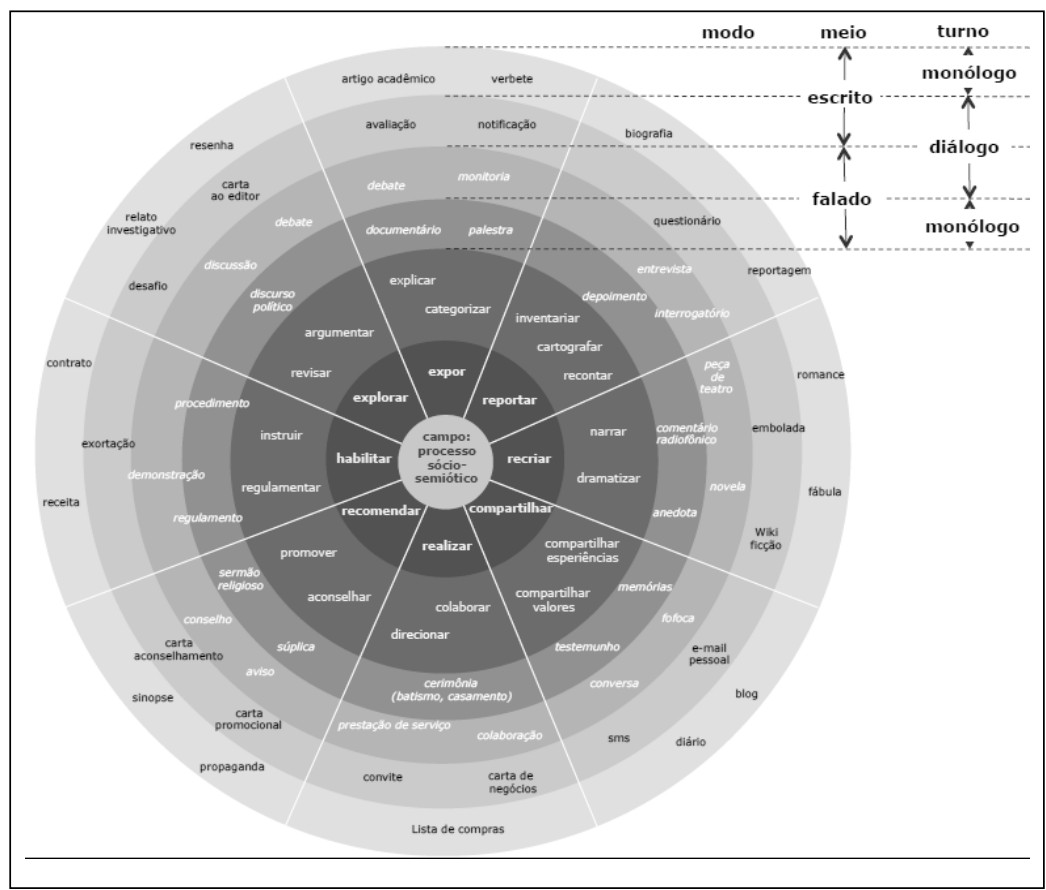

Blogs segundo a tipologia textual baseada em contexto: proposta para análise textual em estudos da tradução

Figura 2 - Esfera de atividades sociossemióticas proposta por Matthiessen, Wu e Teruya (2007), traduzida por Silva e Espindola (2013)

A Esfera de Atividades Sociossemióticas ilustra oito ASSs; as demais camadas contêm exemplos de tipos de textos que realizam as diferentes ASSs, considerando modo e interação verbal: combinação de modo e campo. A camada mais externa, que é o foco da pesquisa em questão, ilustra textos monólogos e escritos, como reportagem, romance, etc., dentre dos quais selecionamos o tipo de texto 'blog'.

Matthiessen (2007) afirma que todas as ASSs têm uma natureza social, mas enquanto algumas são somente sociais, outras são tanto sociais como semióticas, isto é, são atividades sociais que também criam significado. Essa reflexão tem base na distinção feita por Halliday (1978) entre categorias de primeira e segunda ordem dentro de um contexto. Categorias de primeira ordem existem independentemente da linguagem; nestas categorias a linguagem apenas entra para facilitar a atividade, já as de segunda ordem só existem através da linguagem. Somente a ASS Realizar é classificada como de primeira ordem (social); todas as outras sete são classificadas como sendo de segunda ordem (semióticas). Estas são: Expor, Reportar, Recriar, Compartilhar, Recomendar, 
Habilitar e Explorar. Cada uma dessas ASSs ${ }^{12}$ é definida, segundo Matthiessen, Teruya e Lam (2010) como:

Edelweiss

Vitol Gysel

Maria Lúcia

B.de Vasconcellos

Elaine

Espindola

440

I) Realizar: constituídas através de atividades sociais em que a linguagem apenas as facilita e nem sempre as constitui. É a chamada: 'linguagem em ação';

II) Expor: domínios gerais de experiência, descrevendo-os, classificando-os (taxonomizando-os), explicando-os e assim por diante;

III) Reportar: experiências específicas - relatando um fluxo ou um evento específico, ou ainda fazendo um levantamento de uma região ou espaço específico;

IV) Recriar: experiências específicas - normalmente imaginárias, incluindo o recriar de outras atividades sociossemióticas (compartilhar, realizar, recomendar, etc.);

v) Compartilhar: tipicamente experiências e valores pessoais como uma maneira de 'calibrar' relacionamentos interpessoais;

VI) Recomendar: uma linha de ação tanto para promover (beneficiando o falante [exigindo]) como para aconselhar o destinatário a tomar certa atitude ([dando]);

VII) Habilitar: uma linha de ação tanto para dar poder ao falante quanto para regulá-lo;

VIII)Explorar: tipicamente valores ou hipóteses públicas, normalmente comparando e argumentando em favor de uma alternativa.

De acordo com Matthiessen et al (2007, p. 16) em seu texto intitulado English Grammar through text: Text Typology and Grammatica patterns, qualquer tipo de texto é realizado por uma ou mais ASSs, as quais podem estar presentes em diferentes segmentos do mesmo texto, ou até estarem presentes no mesmo segmento de texto simultaneamente (o que ele chama de 'fuzzy regions', neste estudo traduzido como 'regiões mescladas') como no caso das ASSs Compartilhar e Recriar, por exemplo, que podem, respectivamente, compartilhar ou recriar outras ASSs.

12. As definições à seguir, retiradas da obra "Key Terms in SFL" (MATTHIESSEN, TERUYA; LAM, 2010), são traduções feitas pelas autoras desse estudo. 


\subsection{A metafunção ideacional}

$\mathrm{O}$ enfoque da análise deste estudo foi dado à metafunção ideacional, mais precisamente, ao modo experiencial, no qual a linguagem é vista como um sistema modelador do 'conteúdo' de um texto. Thompson (2004) explica que a perspectiva experiencial da LSF nos possibilita reconhecer o 'conteúdo' de uma sentença através da observação das entidades lexicais quanto ao seu comportamento e quanto ao seu relacionamento umas com as outras (p.86).

Segundo Halliday (1994) em seu livro intitulado An introduction to Functional Grammar, o sistema de transitividade constrói um mundo de experiências através de 'tipos de processos'. Esses processos são denominados de processos de transitividade e podem ser classificados em (i) processos materiais; (ii) processos mentais; (iii) processos relacionais; (iv) Blogs segundo a tipologia textual baseada em contexto: proposta para análise textual em estudos da tradução processos comportamentais; (v) processos verbais; (vi) processos existenciais. De acordo com Butt e Matthiesen (2000), o processo é o centro ou o núcleo da oração e ao redor desse núcleo estão os participantes associados ao processo. Tais participantes podem transmitir ao leitor informações suficientes considerando-se o propósito do escritor, mas em alguns casos, o escritor pode acrescentar mais uma camada de significado ao redor do núcleo processo. Essa camada é conhecida como circunstância (CIR), a qual dá mais significado ao processo, como por exemplo, onde/ quando/como/porque/com quem ou como o processo ocorreu.

Este estudo propôs-se a olhar um aspecto no significado geral da oração - a oração como representação - a qual reflete, na gramática, a metafunção experiencial, responsável por construir um modelo de experiência a partir dos 'aconteceres' do mundo externo e do mundo interno de cada indivíduo envolvido no CS. Experiencialmente, a oração constrói experiência como uma configuração de processo, participantes envolvidos neste e as circunstãncias a ele associadas. Considerando o fato de que a oração é o 'locus' de representação de uma interpretação da realidade, o olhar investigativo se concentrou em como cada tipo de texto é representado através de um levantamento dos processos de transitividade emergentes em cada oração com vistas a verificar até que ponto essa representação tem uma relação típica com a ASS à qual tal texto pertence.

O grande diferencial da Tipologia Textual baseada em contexto é o acréscimo da noção de ASSs ao parâmetro de Campo. Dessa forma, Matthiessen et al (2007) possibilitam a aplicação de sua tipologia a textos híbridos, classificando-os não somente quanto a seu propósito 
Edelweiss
Vitol Gysel

Maria Lúcia

B.de Vasconcellos

Elaine

Espindola

retórico, quanto à sua forma ou assunto, mas quanto às "atividades realizadas pelos indivíduos envolvidos no contexto" (MATTHIESSEN et al, 2010 p. 95) podendo tais atividades serem realizadas simultaneamente ou paralelamente dentro de um único texto.

\section{Metodologia}

Segundo a Esfera de Atividades Sociossemióticas proposta por Matthiessen et al em 2007, o tipo de texto 'blog' é classificado como pertencente à ASS Compartilhar, que é definida como "tipicamente o compartilhar de experiências e valores e princípios pessoais como uma maneira de 'calibrar' relacionamentos interpessoais ${ }^{13}$ " (MATTHIESSEN et al. 2010, p. 200).

Apesar de a maioria dos blogs serem primariamente textuais, alguns podem combinar textos escritos, imagens, links para outros blogs e para outras mídias relacionadas com o tema abordado. Sabe-se que, neste caso, o texto completo é o texto com as imagens, ou seja, a ASS inclui todos os elementos do blog. O significado está vinculado ao ambiente onde o texto está inscrito perpassando questões multimodais do tipo: cor, ícones, formatação, disposição, etc. Por razões metodológicas, neste estudo, o texto escrito foi isolado para permitir uma investigação da configuração ideacional em termos léxico-gramaticais. Além disso, deu-se preferência a textos produzidos em ambiente virtual, os quais estejam em consonância com meios de produção e consumo atuais, como por exemplo, websites, blogs, e outros meios digitais; a textos que, no total da soma de suas palavras, não ultrapassem 1.500 palavras em cada idioma, para delimitar o corpus; a textos produzidos sequencialmente no período entre novembro de 2011 e setembro de 2012 para delimitar o recorte referente à abrangência temporal de consultas ao blog, e a textos que contivessem o problema de sobreposição apontado por Bell (1991) e Reiss (1971).

\section{Critérios de seleção e textos selecionados}

Foram selecionados 09 textos em PB e somente 05 textos em IA, pois os textos em português são mais curtos, ou seja, têm um número mais reduzido de palavras, o que gerou a necessidade de um número maior de textos para se chegar a 1.500 palavras. Em contrapartida, os textos em inglês, por serem mais extensos, alcançaram 1.500 palavras com apenas 05 textos.

13. "Sharing typically personal values and experiences to enable interactants to create profiles of one another as a way of "calibrating" interpersonal relationships." 
Os nove textos a seguir foram selecionados do blog em português brasileiro (BPB). O Quadro 1 fornece informações sobre os textos em PB do ambiente do blog 'Lucytrip'.

\begin{tabular}{|c|c|c|c|c|c|}
\hline \multicolumn{6}{|c|}{ Tabela de Informações sobre os textos em PB no ambiente do blog } \\
\hline Texto & $\begin{array}{l}\text { Nome do } \\
\text { texto }\end{array}$ & Língua & $\begin{array}{l}\text { Data de } \\
\text { postagem }\end{array}$ & $\begin{array}{l}\text { Número } \\
\text { de pala- } \\
\text { vras }\end{array}$ & $\begin{array}{l}\text { Domínio de Expe- } \\
\text { riência }\end{array}$ \\
\hline T1 & $\begin{array}{c}\text { A beleza está } \\
\text { nos olhos de } \\
\text { quem vê }\end{array}$ & PB & $11 / 09 / 2012$ & 240 & $\begin{array}{c}\text { Diário: Valores/ } \\
\text { princípios e Experi- } \\
\text { ências }\end{array}$ \\
\hline T2 & Miudezas & $\mathrm{PB}$ & $10 / 09 / 2012$ & 30 & $\begin{array}{l}\text { Diário: } \\
\text { Valores /princípios }\end{array}$ \\
\hline T3 & Olhar e ver & $\mathrm{PB}$ & $15 / 07 / 2012$ & 90 & $\begin{array}{c}\text { Diário: } \\
\text { Valores /princípios }\end{array}$ \\
\hline T4 & Casinha & PB & $20 / 05 / 2012$ & 89 & $\begin{array}{l}\text { Explicação e Valo- } \\
\text { res/princípios }\end{array}$ \\
\hline T5 & Homem nu & $\mathrm{PB}$ & $16 / 05 / 2012$ & 103 & $\begin{array}{c}\text { Diário: } \\
\text { Experiência e } \\
\text { Valores /princípios }\end{array}$ \\
\hline T6 & Chamado & PB & $08 / 04 / 2012$ & 43 & $\begin{array}{c}\text { Diário: } \\
\text { Experiência e } \\
\text { Valores /princípios }\end{array}$ \\
\hline T7 & Sempre ela & PB & $06 / 03 / 2012$ & 268 & $\begin{array}{c}\text { Diário: } \\
\text { Experiência e } \\
\text { Valores /princípios }\end{array}$ \\
\hline T8 & Menininha & PB & $10 / 11 / 2011$ & 320 & $\begin{array}{c}\text { Diário: } \\
\text { Experiência e } \\
\text { Valores /princípios }\end{array}$ \\
\hline T9 & Reputação & PB & $17 / 11 / 2011$ & 195 & $\begin{array}{c}\text { Diário: } \\
\text { Experiência e } \\
\text { Valores /princípios }\end{array}$ \\
\hline
\end{tabular}

Blogs segundo a tipologia textual baseada em contexto: proposta para análise textual em estudos da tradução

Quadro 1 - Informações sobre os textos em PB no ambiente do blog

Os cinco textos selecionados no BIA também têm a característica comum de serem textos escritos para serem lidos. Como mostra o Quadro 2, os textos em IA são mais extensos, mas pelas razões metodológicas referentes às restrições temporais e sequenciais das postagens, procurou-se 
manter a fidelidade a tais critérios de seleção. O Quadro 2 apresenta informações sobre os textos em IA no ambiente do blog 'Kimberlymichelle'.

\begin{tabular}{|c|c|c|c|c|c|c|}
\hline \multirow{2}{*}{$\begin{array}{r}\text { Edelweiss } \\
\text { Vitol Gysel }\end{array}$} & \multicolumn{6}{|c|}{ Tabela de Informações sobre os textos em IA no ambiente do blog } \\
\hline & Texto & Nome do texto & $\begin{array}{l}\text { Lín- } \\
\text { gua }\end{array}$ & $\begin{array}{l}\text { Data de pos- } \\
\text { tagem }\end{array}$ & $\begin{array}{l}\text { Número } \\
\text { de pala- } \\
\text { vras }\end{array}$ & $\begin{array}{l}\text { Domínio de } \\
\text { Experiência }\end{array}$ \\
\hline $\begin{array}{r}\text { Marla Lucia } \\
\text { B. de Vasconcellos } \\
\text { Elaine }\end{array}$ & T10 & $\begin{array}{l}\text { Crying at be- } \\
\text { dtime }\end{array}$ & IA & $06 / 02 / 2012$ & 296 & $\begin{array}{c}\text { Diário: } \\
\text { Experiência e } \\
\text { Valores /prin- } \\
\text { cípios }\end{array}$ \\
\hline Espindola & T11 & $\begin{array}{l}\text { A crafty way to } \\
\text { say 'I love you' }\end{array}$ & IA & $03 / 02 / 2012$ & 140 & $\begin{array}{l}\text { Texto procedi- } \\
\text { mental }\end{array}$ \\
\hline 444 & T12 & $\begin{array}{l}\text { The non-racing } \\
\text { parts of our } \\
\text { Disneyland } \\
\text { weekend }\end{array}$ & IA & $02 / 02 / 2012$ & 501 & $\begin{array}{c}\text { Diário: } \\
\text { Experiência e } \\
\text { Valores /prin- } \\
\text { cípios }\end{array}$ \\
\hline & T13 & $\begin{array}{c}\text { Faith, trust and } \\
\text { dust }\end{array}$ & IA & $27 / 01 / 2012$ & 316 & $\begin{array}{c}\text { Diário: } \\
\text { Experiência }\end{array}$ \\
\hline & T14 & $\begin{array}{l}\text { From a pin: } \\
\text { banana split } \\
\text { cupcakes }\end{array}$ & IA & $25 / 01 / 2012$ & 148 & Conselho \\
\hline
\end{tabular}

Quadro 2 - Informações sobre os textos em IA no ambiente do blog

Pelo fato de ser uma pesquisa qualitativa, o objetivo aqui foi a compreensão dos significados por meio da análise de uma pequena amostra, não havendo a necessidade de apoio em informações estatísticas, uma vez que se pretendeu 'entender' os significados dos resultados e não 'mensurá-los' (PONTE et al, 2007). Entretanto, levando em conta o que Halliday (1973) ressalta, "É possível haver 'turbulência quantitativa' quando um número específico se sobressai e alguns números podem ser muito sugestivos" (p.117), este estudo apresentou parte de seus resultados em números como forma de fortalecer a discussão dos fatos apresentados e discutidos.

\subsection{Critérios de classificação}

Para o reconhecimento do CS de cada texto, foram selecionados critérios de classificação baseados em Matthiessen et al (2007). Tais critérios consideram o Campo, Relações e Modo, que por sua vez são subdivi- 
didos em Domínio de Experiência e ASS dentro de Campo, em Papéis Institucionais e Distância dentro de Relações, e em Meio e Turno dentro de Modo. O Quadro 3 apresenta o que Matthiessen et al (2007) chamam de "ambientes de significado no CS":

\begin{tabular}{|c|c|c|c|c|c|}
\hline \multicolumn{6}{|c|}{ Contexto de Situação } \\
\hline \multicolumn{2}{|c|}{$\begin{array}{c}\text { Atividade } \\
\text { (Campo) }\end{array}$} & \multicolumn{2}{|c|}{$\begin{array}{l}\text { Participantes } \\
\text { (Relações) }\end{array}$} & \multicolumn{2}{|c|}{$\begin{array}{l}\text { Linguagem } \\
\text { (Modo) }\end{array}$} \\
\hline $\begin{array}{c}\text { Domí- } \\
\text { nio de } \\
\text { Experi- } \\
\text { ên-cia }\end{array}$ & $\begin{array}{l}\text { Ativida- } \\
\text { de Sócio } \\
\text { Semió- } \\
\text { tica }\end{array}$ & $\begin{array}{c}\text { Papéis Ins- } \\
\text { titucio } \\
\text { nais }\end{array}$ & Distância & Meio & Turno \\
\hline $\begin{array}{l}\text { Assunto } \\
\text { (Diário, } \\
\text { Biogra- } \\
\text { fia, Con- } \\
\text { selho, } \\
\text { Manual } \\
\text { de ins- } \\
\text { truções, } \\
\text { etc.) }\end{array}$ & $\begin{array}{l}\text { Realizar } \\
\text { Expor } \\
\text { Reportar } \\
\text { Recriar } \\
\text { Compar- } \\
\frac{\text { tilhar }}{\text { Reco-- }} \\
\text { mendar } \\
\text { Habilitar } \\
\text { Explorar }\end{array}$ & $\begin{array}{c}\text { Papel ou } \\
\text { 'status' de } \\
\text { cada Partici- } \\
\text { pante } \\
\text { (Pai, mãe, } \\
\text { filho, amigo, } \\
\text { leitor, au- } \\
\text { tora e leitor } \\
\text { do blog, } \\
\text { etc.) }\end{array}$ & $\begin{array}{c}\text { Grau de } \\
\text { familia- } \\
\text { ridade } \\
\text { entre os } \\
\text { Partici- } \\
\text { pantes } \\
\\
\text { (Familiar/ } \\
\text { íntima ou } \\
\text { Estranho/ } \\
\text { sem inti- } \\
\text { midade) }\end{array}$ & $\begin{array}{c}\text { Escrito } \\
\text { Falado } \\
\begin{array}{c}\text { Sinaliza- } \\
\text { do }\end{array} \\
\text { Ilustrado }\end{array}$ & $\begin{array}{l}\text { Dialógico } \\
\text { Monoló- } \\
\text { gico }\end{array}$ \\
\hline
\end{tabular}

Blogs segundo a tipologia textual baseada em contexto: proposta para análise textual em estudos da tradução

\section{Quadro 3 - Os ambientes de significado no Contexto de Situação}

(MATTHIESSEN et al., 2007)

O Domínio de Experiência, ou seja, o assunto sobre o qual o texto trata, é a única categoria dentro de Campo nas outras tipologias textuais. O grande diferencial da Tipologia Textual Baseada em Contexto é que ela define, por assim dizer, uma segunda categoria dentro de Campo: a ASS, que é exatamente aquilo que está acontecendo dentro do CS, mais especificamente, é a atividade que está sendo realizada pelos participantes envolvidos no contexto. Matthiessen et al (2007) esclarecem que as distinções feitas pelas ASSs podem ser, em certos casos, um tanto 'mescladas', como por exemplo em propagandas informativas que reportam sobre e recomendam algo, ou como em biografias de ficção que mesclam Reportar e Recriar. A classificação sociossemiótica dos quatorze textos foi realizada com base na esfera proposta por Matthiessen et al. (2007). Primeiro, constatou-se que a categorização dos textos em questão como parte de um blog é feita por Matthiessen como pertencentes à ASS: Compartilhar. Depois da leitura de cada texto foi feita 
Edelweiss
Vitol Gysel

Maria Lúcia

B.de Vasconcellos

Elaine

Espindola uma comparação com as definições dadas por Matthiessen et al. (2010) da ASS em questão. No reconhecimento do CS de cada texto, todos os critérios (Campo, Relações e Modo) foram dispostos em forma tabular, mas, cumpre esclarecer que mais esforço foi enfocado à variável Campo.

\subsection{Procedimentos para a análise de transitividade}

Seguindo a sugestão de Matthiessen et. al em 2007 (p.3), um olhar mais detalhado do texto aumentando o grau de especificidade e levando em conta um possível hibridismo textual se faz necessário, com vistas à identificação de outras ASSs presentes em diferentes segmentos do texto. Para tanto, uma comparação com as definições de Matthiessen et al (2007) das ASSs reconhecidas em diferentes segmentos dos textos confirmam as definições dadas. Após tal comparação, uma análise em nível oracional dos dados foi feita com enfoque nos tipos de processos e com base no sistema de transitividade. Para tanto, os processos, os participantes e as circunstâncias foram etiquetados manualmente e os resultados foram dispostos em forma tabular, seguindo $<$ Pro $>,<$ Par $>$ e < Cir>, contendo as classificações do quadro a seguir:

\begin{tabular}{|c|c|c|}
\hline Processos & Participantes & Circunstâncias \\
\hline Material & Ator/Meta/Extensão/Beneficiario & $\begin{array}{l}\text { De extensão } \\
\text { De localização }\end{array}$ \\
\hline Mental & Experienciador/Fenômeno & $\begin{array}{l}\text { De modo } \\
\text { De causa }\end{array}$ \\
\hline Relacional & $\begin{array}{l}\text { Portador/Atributo } \\
\text { Identificador/Identificado } \\
\text { Característica/Valor }\end{array}$ & $\begin{array}{l}\text { De contingência } \\
\text { De acompanhamento } \\
\text { De papel } \\
\text { De assunto }\end{array}$ \\
\hline Verbal & $\begin{array}{l}\text { Dizente/Receptor/Verbiagem/ } \\
\text { Alvo }\end{array}$ & De ângulo \\
\hline $\begin{array}{l}\text { Comporta- } \\
\text { mental }\end{array}$ & Comportante & \\
\hline Existencial & Existente & \\
\hline
\end{tabular}

Quadro 4 - Relação dos Participantes, Processos e Circunstâncias do sistema de transitividade ${ }^{14}$

14. Tabela inspirada em MARTIN; MATTHIESSEN; PAINTER, 1997. 


\subsection{Procedimentos para a comparação dos resultados dos dois corpus}

Após a análise da transitividade, uma comparação entre as orações em português e inglês foi feita, em termos de sua realização nas diversas ASSs presentes nos textos. Essa comparação está apresentada em dois gráficos visualizando os processos de transitividade dos nove textos em português e dos cinco textos em inglês (ver 3. Análise de Dados). A partir dessa comparação estruturaram-se padrões de diferenças e/ou semelhanças do perfil ideacional entre os textos em português e inglês.

\section{Análise dos dados}

Halliday (1978, p. 146) distingue entre Ato de Narração e Conteúdo de Narração. $O$ primeiro diz respeito ao que estava acontecendo durante a produção do texto e por que, ou seja, com que finalidade ele foi produzido. O segundo diz respeito ao texto em si, sua forma e seu conteúdo. O que Halliday chama de Conteúdo de Narração, Matthiessen mais tarde, em 2007, chama de Domínio de Experiência. Por essa razão o Campo, neste estudo, é analisado a partir de duas classificações, ASSs e Domínio de Experiência. A classificação do Domínio de Experiência de cada texto é baseada nas sugestões propostas na esfera de ASSs proposta por Matthiessen et al em 2007. As classificações quanto a Relações e Modo têm sua base na tabela apresentada por Matthiessen (2007, p.15), intitulada First and second order field, tenor and mode.

Apresenta-se, abaixo, a análise dos 'blogs' em Português Brasileiro (PB) e dos 'blogs' em Inglês Americano (IA). Os primeiros nove textos analisados e dispostos em forma tabular abaixo foram selecionados do blog em PB.

\begin{tabular}{|c|c|c|c|c|c|}
\hline \multicolumn{6}{|c|}{ Contexto de Situação } \\
\hline \multicolumn{6}{|c|}{9 Textos em Português Brasileiro } \\
\hline \multicolumn{2}{|c|}{$\begin{array}{l}\text { Atividade } \\
\text { (Campo) }\end{array}$} & \multicolumn{2}{|c|}{$\begin{array}{c}\text { Participantes } \\
\text { (Relaçôes) }\end{array}$} & \multicolumn{2}{|c|}{$\begin{array}{c}\text { Linguagem } \\
\text { (Modo) }\end{array}$} \\
\hline $\begin{array}{l}\text { Domínio de } \\
\text { Experiência }\end{array}$ & $\begin{array}{c}\text { Ativida- } \\
\text { de Sócio } \\
\text { Semió- } \\
\text { tica }\end{array}$ & $\begin{array}{c}\text { Papéis } \\
\text { Institu- } \\
\text { cionais }\end{array}$ & Distância & Meio & Turno \\
\hline $\begin{array}{c}8 \text { Diários } \\
5 \text { Valores e } \\
\text { Experiên- } \\
\text { cias } \\
2 \text { Valores } \\
1 \text { Experiên- } \\
\text { cia } \\
1 \text { Explicação }\end{array}$ & $\begin{array}{l}\text { Compar- } \\
\text { tilhar } \\
\text { Reportar } \\
\text { Recriar } \\
\text { Expor } \\
\text { Reco- } \\
\text { mendar }\end{array}$ & $\begin{array}{c}\text { Autora e } \\
\text { leitor } \\
\text { Pessoas } \\
\text { envolvi- } \\
\text { das nos } \\
\text { relatos }\end{array}$ & $\begin{array}{c}\text { 6 Estra- } \\
\text { nho sem } \\
\text { intimidade } \\
\text { 3 Familiar } \\
\text { / íntima }\end{array}$ & $\begin{array}{l}\text { Escri- } \\
\text { to }\end{array}$ & $\begin{array}{l}\text { Monológico } \\
1 \text { Texto } \\
\text { contém um } \\
\text { segmento } \\
\text { dialógico }\end{array}$ \\
\hline
\end{tabular}

Quadro 5 - Textos em PB inseridos em seus respectivos CSs 
Levando em consideração a localização dos textos em PB em seus respectivos CSs, pôde-se observar que, em termos de Domínio de Experiência, 8 textos são diários, 5 deles compartilham valores/princípios e Edelweiss experiências, 2 compartilham somente valores/princípios, 1 comparVitol Gysel tilha somente uma experiência e 1 texto é uma explicação e não um diário. Assim, as ASSs realizadas através dos textos em PB são ComparMaria Lúcia tilhar, Recriar, Reportar, Expor e Recomendar. Em termos de Papéis B. de Vasconcellos Institucionais, os envolvidos nos relatos são a autora e o leitor e, em alguns textos, a autora narra situações que envolvem pessoas. Quando

Elaine os Papéis Institucionais se limitam em autora e leitor, a Distância entre Espindola eles é estranha e sem intimidade, o que acontece em 6 textos, quando a autora inclui em seu relato outras pessoas. Por outro lado, a Distância passa a ser Familiar ou íntima, o que acontece em 3 textos; em termos de Modo, o Meio é escrito em todos os textos, e o Turno é sempre monológico, com exceção de um texto que contém um segmento dialógico.

Os próximos cinco textos analisados e dispostos em forma tabular provêm do blog em IA:

\begin{tabular}{|c|c|c|c|c|c|}
\hline \multicolumn{6}{|c|}{ Contexto de Situação } \\
\hline \multicolumn{6}{|c|}{5 Textos em Inglês Americano } \\
\hline \multicolumn{2}{|c|}{$\begin{array}{c}\text { Atividade } \\
\text { (Campo) }\end{array}$} & \multicolumn{2}{|c|}{$\begin{array}{c}\text { Participantes } \\
\text { (Relações) }\end{array}$} & \multicolumn{2}{|c|}{$\begin{array}{c}\text { Linguagem } \\
\text { (Modo) }\end{array}$} \\
\hline $\begin{array}{c}\text { Domínio } \\
\text { de Experi- } \\
\text { ência }\end{array}$ & $\begin{array}{c}\text { Atividade } \\
\text { Socios- se- } \\
\text { miótica }\end{array}$ & $\begin{array}{l}\text { Papéis Ins- } \\
\text { titucionais }\end{array}$ & Distância & Meio & Turno \\
\hline $\begin{array}{l}3 \text { Diários } \\
2 \text { Experi- } \\
\text { ência } \\
\text { e Valores } \\
1 \text { Experi- } \\
\text { ência } \\
1 \text { Manual } \\
1 \text { Conselho }\end{array}$ & $\begin{array}{l}\text { Comparti- } \\
\text { lhar } \\
\text { Reportar } \\
\text { Expor } \\
\text { Recomen- } \\
\text { dar } \\
\text { Habilitar }\end{array}$ & $\begin{array}{l}\text { Autora e } \\
\text { leitor } \\
\text { Pessoas en- } \\
\text { volvidas nos } \\
\text { relatos }\end{array}$ & $\begin{array}{c}2 \text { Familiar } \\
1 \text { Familiar e } \\
\text { Estranho/ } \\
\text { sem intimi- } \\
\text { dade } \\
2 \text { Estra- } \\
\text { nhos/ sem } \\
\text { intimidade }\end{array}$ & Escrito & $\begin{array}{c}\text { Monológico } \\
2 \text { Textos } \\
\text { contêm um } \\
\text { segmento } \\
\text { dialógico }\end{array}$ \\
\hline & & & & & \\
\hline
\end{tabular}

Quadro 6 - Textos em IA inseridos em seus respectivos CSs

Levando em consideração a localização dos textos em IA em seus respectivos CSs, pôde-se observar que em termos de Domínio de Experiência 3 textos são diários, 2 deles compartilham valores/princípios e experiências, 1 compartilha somente uma experiência, 2 textos não são 
diários: 1 é um manual e 1 é um conselho. As ASSs realizadas através dos textos em IA são: Compartilhar, Reportar, Expor, Recomendar e Habilitar. Em termos de Papéis Institucionais, os envolvidos nos relatos são a autora e o leitor e, em alguns textos, a autora narra situações que envolvem pessoas. Quando os Papéis Institucionais se limitam a autora e leitor, a Distância entre eles é estranha e sem intimidade, o que acontece em 2 textos; entretanto, quando a autora inclui em seu relato outras pessoas e elas são familiares, a Distância passa a ser Familiar ou íntima, o que acontece em 2 textos. Já em 1 texto a autora começa seu relato com uma situação familiar envolvendo pessoas da família, nesse caso a Distância é Familiar, mas em um segundo momento no mesmo texto a autora se distancia da situação e faz reflexões sobre ela, interagindo somente com o leitor, nesse ponto, a Distência se torna estranha e sem

Blogs segundo a tipologia textual baseada em contexto: proposta para análise textual em estudos da tradução intimidade. Em termos de Modo, o Meio é escrito em todos os textos, e o Turno é sempre monológico, com exceção de dois textos que contêm um segmento dialógico cada.

Pelo fato de os textos, aqui selecionados, fazerem parte de Blogs e assim serem compartilhamentos das autoras, já se partiu de princípio que textos de blogs realizam a ASS Compartilhar. Em definição, Compartilhar realiza tipicamente o compartilhar de valores/princípios pessoais e experienciais, a fim de possibilitar a quem fala/escreve e ouve/lê a criação de perfis uns dos outros como um meio de "calibrar" relacionamentos interpessoais. Desta forma, a ASS pode compartilhar experiências/situações e valores/princípios. Além disso, ela é um tipo de atividade semiótica que diz respeito a relações; isso significa uma negociação em um terreno neutro - consenso entre os falantes/escritores e ouvintes/leitores (ex. reforçar ideias e valores/princípios já estabelecidos em uma determinada sociedade) ou identificar áreas de conflito (ex. fornecer impulso semiótico para uma grande e longa amizade). Tipicamente, contextos de compartilhamento são conversas cara a cara realizadas em particular (espaço físico comum entre os participantes) - incluindo papo, piada, fofoca e opinião. Contudo, a tecnologia expandiu a abrangência da conversa casual para incluir formas diferentes de papo online e (com graus variados de demora nas trocas) mensagens de texto via celular, mensagens de email e blogs, onde os leitores têm a possibilidade de deixar suas opiniões ao final de cada postagem, possibilitando assim uma troca interpessoal tanto com o autor como com os demais leitores do blog. 
Para fins de cotejar a descrição dos textos em termos de ASSs com sua descrição em termos de processos do sistema de transitividade tipicamente esperados para a realização de cada ASS, foi realizada uma

Edelweiss

Vitol Gysel

Maria Lúcia

B. de Vasconcellos

Elaine

Espindola análise dos processos de transitividade de cada texto. Através dessas análises procurou-se traçar o perfil experiencial de cada texto, perfil esse que tem como base os processos emergentes nas análises. Todos os textos realizam a ASS Compartilhar, seja em termos de experiências ou princípios e valores. Entretanto, por sua frequência constante e por razões de espaço editorial, a ASS Compartilhar não aparece na Figura 3, que apresenta a comparação dos resultados das ASS que fazem uma maior distinção entre os textos analisados em PB.

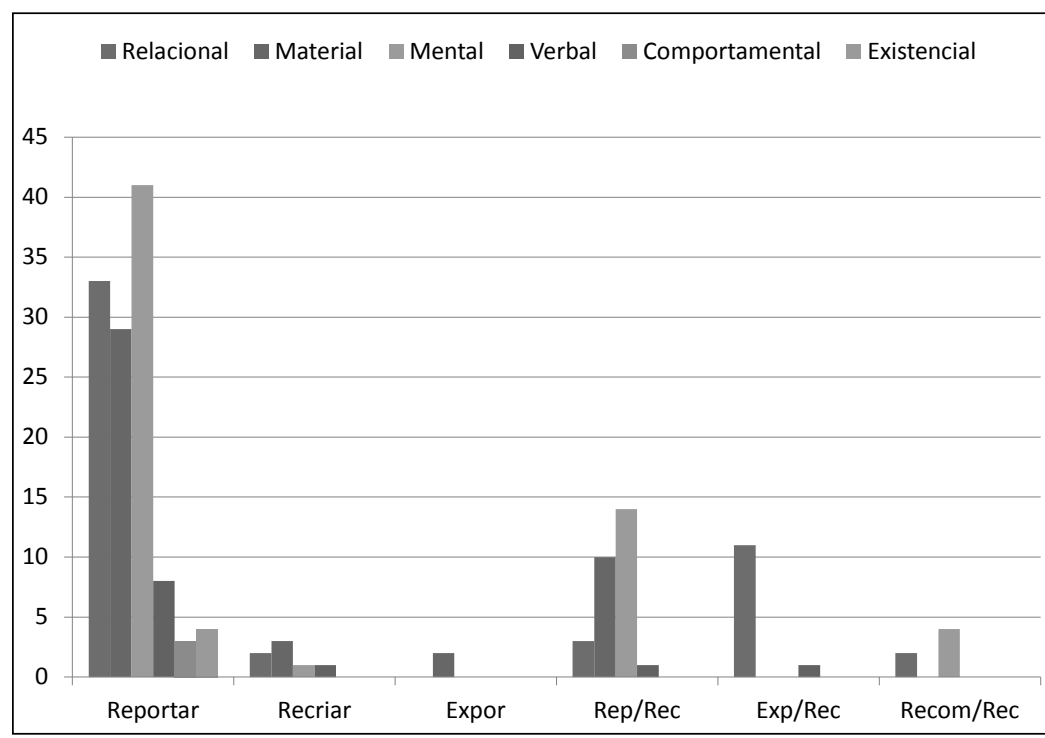

Figura 3 - Relação entre ASSs e Processos de Transitividade realizados nos textos em PB

A Figura 3 ressalta a predominância de textos que realizam a ASS Reportar em PB, o que pode ser associado ao fato de que, segundo a esfera de ASSs (MATTHIESSEN et al. 2007), em um blog, os textos que realizam a ASS Compartilhar aparesentam relatos e reportam fatos, experiências, sentimentos, pensamentos, etc. Além disso, após a observeção do Domínio de Experiência, classificação sociossemiótica e análise de transitividade de cada texto, observou-se que as unidades selecionadas nesse blog têm, em sua maioria, um aspecto em comum - um 'tom' poético reconhecido por sua forma, ritmo e estrutura -, razão pela qual foram classificados também como pertencentes à ASS Recriar. 
A Figura 3 mostra como o fluxo de eventos é construído em termos de processos de transitividade em textos que reportam ou recriam ou expõem, e textos que realizam duas ou mais ASSs simultaneamente, como Reportar e Recriar, Expor e Recriar e Recomendar e Recriar. Visualizando as escolhas feitas no decorrer dos textos, pode-se ter uma visão clara de como processos de transitividade se complementam em cada ASS. Neste sentido, a figura mostra que o processo de transitividade mais recorrente na ASS Reportar foi o Mental, ou seja, quando a autora compartilhou textos que reportam, ela salientou suas percepções, pensamentos e sentimentos. Orações relacionais também têm um papel importante, pois através delas a autora identifica entidades e atribui valores a elas. Orações materias, nesse caso, refletem as ações realizadas pelos participantes envolvidos. As orações verbais, comportamentais e existenciais, apesar de terem uma pequena ocorrência, significam variações dentro dos relatos da autora, onde ela não mais refletiu, identificou ou descreveu ações, mas reportou a existência dos participantes (Existentes), o que eles falaram (Verbiagens) e como se comportaram. Ocorrências semelhantes, ou seja, na maioria mental, seguido de relacional e de material, aconteceram quando houve hibridismo entre ASSs - Reportar e Recriar. A diferença está apenas no 'tom' e na 'forma' mais poética. A ASS Expor foi realizada através de duas orações materiais, em que estas orações expõem as ações dos Participantes, diferentemente da ASS Reportar.

Quando o texto foi realizado pelas ASSs Recomendar e Recriar, as realizações em termos de transitividade mostraram que o processo de transitividade mental foi o mais recorrente seguido dos relacionais e e dos materiais. De uma maneira geral o cognitivo, representado por meio do processo de transitividade mental, foi ressaltado na maior parte dos textos selecionados do blog em PB. Vale mencionar que o texto classificado como ASSs Expor e Recriar é um relato topográfico no qual a autora descreve desenhos de casinhas, identificando entidades e atribuindo valores e características a elas. A maior ocorrência de orações relacionais nesse texto confirmou o que a proposta expõe: "Relatos topográficos são atemporais, são constituídos por figuras do ser e realizados por orações relacionais ${ }^{15 "}$ (MATTHIESSEN et al, 2010, p. 183).

$O$ padrão emergente nos textos em PB pode ser definido da seguinte maneira: primeiramente, todos os textos compartilham: alguns somente valores/princípios, outros, experiências e valores/princípios, e outros, ainda, somente experiências. Além de compartilhar, uma grande porcentagem deles

15. "Topographic reports are atemporal; they are made up of figures of being, realized by relational clauses." 
também reporta e quando reporta o faz principalmente por meio de processos de transitividade mentais. Isso pode ser justificado, pois a ASS Recriar também é realizada em vários textos sob forma de 'linguagem poética' (Domínio de ExEdelweiss periência), a qual faz reflexões sobre os participantes e suas ações. Logo depois, Vitol Gysel os textos selecionados desse blog refletem um hibridismo entre duas ou mais ASSs, por exemplo, o texto 3, Sempre ela, que compartilha recriando segmentos

Maria Lúcia

B. de Vasconcellos

Elaine

Espindola que se alternam entre Recomendar, Expor e Reportar. O texto 5, Homem nu, que compartilha um texto de natureza poética, que também recria; além disso, os textos analisados que expõem, fazem-no por meio do processo de transitividade rRelacional, confirmando o que diz teoria.

Os textos selecionados do blog em IA também foram realizados em sua maioria pela ASS Reportar, mas seu comportamento transitivo foi um tanto diferente dos textos classificados como pertencentes à mesma ASS em PB. A Figura 4 apresenta as realizações transitivas em cada ASS dos textos em IA.

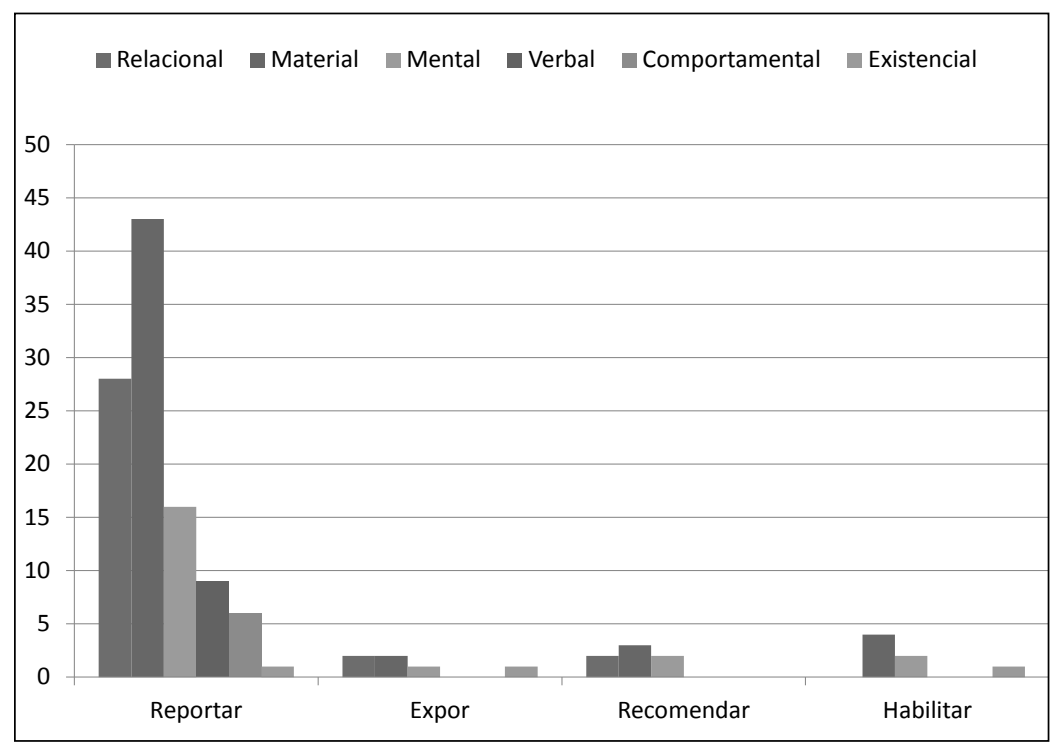

Figura 4 - Relação entre ASSs e processos de transitividade realizados nos textos em IA

A Figura 4 demonstra que o processo de transitividade material predominou na maioria das orações pertencentes à ASS Reportar. Esse resultado pode significar que a autora do blog reportou experiências e situações nas quais enfatizou as ações realizadas pelos participantes. A identificação de participantes, pensamentos e reflexões associados a eles tiveram certo destaque nesta ASS, assim como os processos de transitividade verbal, comportamental e existencial, que também tiveram 
uma contribuição, ainda que pequena, para a construção de significado desta ASS. Um segmento de texto em IA foi classificado como ASS Expor. Como já mencionado anteriormente, a ASS Expor é tipicamente realizada por orações relacionais e esse segmento de texto não fugiu à regra. Nele, foram realizados o processo de transitividade relacional, assim como material, ou seja, a autora identificou entidades e expôs as ações dos participantes. Uma pequena, mas significativa presença do processo de transitividade existencial também foi importante neste segmento, pois através dele a autora introduziu uma nova perspectiva ao texto.

Quando os textos Recomendaram, as orações materiais foram as mais frequentes, seguidas das mentais e relacionais. Aqui, as recomendações focaram, sobretudo, nas ações dos participantes. Quando os textos Habilitaram, também foram empregados processos de transitividade materiais, seguidos de processos de transitividade mentais e uma pequena participação do processo de transitividade existencial. Isso quer dizer que a autora orientou dando passos a serem seguidos em forma de ações, os quais puderam gerar reflexões e pensamentos.

$O$ padrão que emerge nos textos em IA difere em certos aspectos do padrão emergente em PB. Nos textos em IA, a autora compartilha reportando, sobretudo, experiências, realizadas em sua maioria por processos de transitividade materiais. Quando o texto recomenda ou habilita, os processos de transitividade materiais também se destacam. Isso significa que as ações e reações dos participantes são o foco dos relatos nesse blog.

Considerando os resultados das análises e a fim de comparar os resultados dos textos em $\mathrm{PB}$ com os resultados das análises dos textos em IA, procurou-se considerar diferenças e semelhanças entre eles. No que tange às semelhanças, todos os textos analisados neste estudo fazem parte de blogs; por essa razão e com base na esfera de ASSs (MATTHIESSEN et al., 2007) são classificados como Compartilhar; todos os textos compartilham experiências e/ou valores/princípios. Da mesma forma, em termos de Domínio de Experiência, a maior parte dos textos são Diários como registro de experiência pessoal que podem ser divididos em dois tipos: D1 que compartilha experiências e situações cotidianas, ou D2 que compartilha valores e princípios sendo que alguns textos podem compartilhar tanto experiências como valores/princípios; a maioria dos textos em PB e em IA é classificada como ASS Reportar, além da ASS Compartilhar. Isso ocorre porque tipicamente quando se 
Edelweiss
Vitol Gysel

Maria Lúcia

B.de Vasconcellos

Elaine

Espindola

compartilha uma experiência, um fato ou uma situação, reporta-seo ocorrido; assim como nos textos pertencentes à ASS Reportar em PB, os textos que reportam em IA também mostraram que os Processos de Transitividade com menos ocorrência, os quais são verbais, comportamentais e existenciais também contribuíram para a construção de significado nos textos.

Textos que reportam, no âmbito deste estudo, realizaram-se através de contribuições de todos os seis Processos de Transitividade, são eles: relacional, material, mental, verbal, comportamental e existencial. 0 resultado significa que, quando se reporta, o relato se desenvolve alternando a descrição de ações, a identificação de entidades, refletindo sobre elas, assim como confirmando a existência de participantes, relatando falas e diálogos entre eles e seus comportamentos.

Como já mencionado, existem diferenças relevantes entre os textos em PB e os textos em IA que merecem discussão. A primeira diferença, que chamou mais a atenção além do idioma, é o 'tom' dos textos. A autora do blog em PB escreve seus textos de uma forma mais literária com forma e ritmo que chegam a se assemelhar com poesia. A autora do blog em IA escreve seus textos de forma mais informal, como se estivesse realmente escrevendo um diário, conversando com seu leitor. A segunda diferença que pode ser associada à primeira, é o que se compartilha. Nos textos em PB a autora dá preferência ao compartilhar de valores e princípios por meio de reflexões. Mesmo compartilhando uma experiência, ela tenta transmitir seus princípios, talvez por isso, o tom mais formal e literário. Já a autora dos textos em IA compartilha suas experiências em forma de relato e ressaltando algum tipo de moral ou valores/princípios apenas por meio dos relatos, sem fazer uma reflexão explícita. Em termos de Domínio de Experiência, a maior parte dos textos é classificada como Diário, mas enquanto os textos em PB são diários que registram valores e princípios morais, os textos em IA são diários que registram experiências pessoais. Quanto ao perfil ideacional, os textos em PB que, de uma forma geral, compartilharam valores e princípios, apresentaram predominância de orações mentais, enquanto os textos em IA, que compartilharam experiências da autora, apresentaram uma redominância de orações materiais. Isto leva a entender que, tipicamente, quando se compartilham valores/princípios como uma forma de calibrar as 
relações interpessoais -através da externalização de tais valores/ princípios, o autor eo leitor podem se identificar um com o outro -, os eventos realizados no texto são predominantemente cognitivos. Por outro lado, quando compartilhamos apenas experiências, orações materiais que descrevem as ações realizadas pelos participantes têm predominância.

Blogs segundo a tipologia textual baseada em contexto:

\section{Considerações finais}

Levando em consideração o objetivo geral deste artigo, que é estender o modelo de Tipologia Textual baseada em Contexto para os Estudos da Tradução e verificar sua contribuição para a caracterização de textos, pode-se afirmar, com base nos resultados deste estudo, que o modelo aqui apresentado pode contribuir para a Tipologia Textual aplicada até então na área de Estudos da Tradução dando uma nova perspectiva através da utilização de conceitos baseados na noção de ASSs. O fato de a pesquisa ter colocado a Tipologia Textual baseada em Contexto em diálogo com o ramo descritivo dos Estudos da Tradução possibilitou contribuir para a classificação de tipos textuais, visando oferecer ao tradutor ferramentas para o reconhecimento do tipo de texto a que pertence o texto a ser traduzido. Em função da perspectiva a partir da qual o modelo é construído, torna-se possível (para o pesquisador e eventualmente para o tradutor) identificar a natureza sociossemiotica do texto nas línguas em relação tradutória e perceber as realizações típicas de cada ASS. Este conhecimento pode contribuir para a fase de 'reconhecimento de texto' que precede o início da tradução propriamente dita, fornecendo ferramentas de apoio para a execução da tarefa tradutória.

A Tipologia Textual baseda em Contexto contribui para mostrar como a diferenciação entre tipos de texto pode se dar considerando-se as atividades realizadas pelos indivíduos envolvidos no CS no momento em que se cria o texto. Isso possibilita uma classificação de textos produzidos na atualidade como, por exemplo, textos da mídia digital e assistidos por computador. Além disso, este estudo mostrou que o problema de sobreposição, ressaltado por Bell em 1991, pode ser resolvido com a Tipologia Textual baseada em Contexto, pois essa não somente reconhece um possível hibridismo em textos como o classifica e o justifica. proposta para

análise textual em estudos da tradução 


\section{Referências}

BELL, R. T. Translation and translating: Theory and Practice.

Edelweiss

Vitol Gysel

Maria Lúcia

B. de Vasconcellos

Elaine

Espindola

456
London: Longman, 1991.

BUTT, D. G., MATTHIESSEN, C. M. I. M. The meaning potential of language: mapping meaning systemically. Mimeo: Centre for language in Social Life, Macquarie University, 2000.

HALLIDAY, M.A.K. Explorations in the Functions of Language. London: Edward Arnold, 1973.

HALLIDAY, M. A. K. Language as a social semiotic: the social interpretation of language and meaning. London: Edward Arnold, 1978.

HALLIDAY, M. A. K. An Introduction to Functional Grammar. London: Edward Arnold, 1994.

HALLIDAY, M. A. K., HASAN, R. Language, context, and text: aspects of language in a social semiotic perspective. Geelong: Deakin University, 1985.

MATTHIESSEN, C. M. I. M. English grammar through text: text typology and grammatical patterns. Department of Linguistics, Macquarie University; Centre for Language in Social Life, Macquarie University; Systemic Meaning Modelling Group; Halliday Centre for Intelligent Applications of Language Studies, Hong Kong City University, 2007.

MATTHIESSEN, C. M. I. M. et al. Text Analysis for translation and interpreting. Manuscrito, 2009.

MATTHIESSEN, C. M. I. M.; WU, C.; TERUYA, K. English Grammar through text: Text Typology and grammatica patterns. 2007.

MATTHIESSEN, C. M. I. M.; TERUYA, K.; LAM, M. Key terms in Sistemic Funcitional Linguistics. London and New York: Continuum International Publishing Group, 2010. 
PONTE, V. M. R. et al. Análise das metodologias e técnicas de pesquisas adotadas nos estudos brasileiros sobre balanced scorecard: um estudo dos artigos publicados no período de 1999 a 2006. In: AnpCONT, 1., 2007. Gramado Anais... Gramado, 2007. CD-ROM.

REISS, K. Möglichkeiten und Grenzen der Übersetzungskritik. Munich: Max Hueber, 1971.

Blogs segundo a tipologia textual baseada em contexto: proposta para

REISS, K. Translation criticism - the potencials \& limitations. Trad. RHODES, E., F. Manchester, New York: St. Jerome Publishing, 2000.

MATTHIESSEN et al (2007).English grammar through text: text análise textual em estudos da tradução

typology and grammatical patterns. Key notes (2) at the Fourth International Congress on English Grammar (ICEG 4), PSNA College, Dindigul, Tamil Nadu, India, 8-12 January 2007.

THOMPSON, G. Introducing Functional Grammar. $2^{\text {nd }}$. ed. New York: Oxford University Press Inc., 2004, pp. 87-90. 
